\title{
More Than a Deadly Virus: COVID-19 and Its Psychological Impact on American and Canadian Dental Practitioners
}

\author{
Jasbir D. Upadhyaya, Vimi Sunil Mutalik, Mê-Linh Lê, and Dieter J. Schönwetter
}

\section{ABSTRACT}

Objectives: The COVID-19 pandemic has significantly affected dental professionals, thus contributing to adverse psychological outcomes. The aim of this cross-sectional study was to investigate the psychosocial state of American and Canadian dental practitioners, with special emphasis on their affective well-being (both during lockdown and after re-opening), behavioral impact and cognitive responses.

Methodology: Dental practitioners in Canada and USA were invited to participate in an online survey after the initial lockdown period. The questions evaluated the pandemic's effect on affective, behavioral, and cognitive responses.

Results: A total of 587 practitioners completed the online survey. The strongest emotions experienced during the lockdown were sadness followed by fear. Female practitioners, those in the 35-44 age group, and those with less work experience reported higher scores on fear. Following lockdown, participants reported higher anticipation. Males expressed higher feelings of disgust and anger during both phases. Canadians were trustful of the situation in both phases of the pandemic, whereas the emotions of Americans were more towards disgust. About 56.7\% practitioners provided teledentistry during lockdown, mainly through video calling, with Canadians being significantly more involved than the American participants. The highest scores for participants' experiences during lockdown were for a lack of social interaction, followed by concern for contracting infection, and stress from distressing media coverage. Most practitioners were very receptive of receiving the COVID-19 vaccine.

Conclusions: The emotions and behaviors of dental practitioners varied significantly during and after the initial lockdown, highlighting their psychosocial state during the pandemic. The scarcity of literature focusing on these basic emotions during similar outbreaks calls attention for pursuing more research in these areas as they significantly contribute to the overall psychological health of professionals, especially in times of crises. Given the emotions reported by dental practitioners, it would be of value to develop standardized protocols and provide remote psychological support during such periods of uncertainty.

Keywords: Affect, behavior, cognition, crisis, dental practitioners, pandemic.

\section{INTRODUCTION}

COVID-19 has resulted in a significant global impact resulting in over 4.53 million deaths. Its declaration as a global pandemic by the World Health Organization triggered the suspension of all work operations including healthcare institutions [1]. The highly contagious nature of the severe acute respiratory syndrome coronavirus 2 (SARS-CoV-2), and the unique nature of dentistry, make oral healthcare professionals more vulnerable to contracting the infection [2], [3]. In light of this, all elective dental procedures were suspended during the lockdown period. Significant lifestyle changes such as social distancing, changed work conditions,
Published Online: December 12, 2021

ISSN: $2684-4443$

DOI: $10.24018 /$ ejdent.2021.2.6.121

Jasbir D. Upadhyaya*q

Southern Illinois University, School of Dental Medicine, Alton, IL, USA.

(e-mail: jupadhy@ siue.edu)

Vimi Sunil Mutalik

University of Manitoba, Dr. Gerald Niznick Hygiene, Rady Faculty of Health Sciences, Winnipeg, MB, Canada.

(e-mail: vimi.mutalik@umanitoba.ca)

Mê-Linh Lê

University of Manitoba, Neil John Maclean Health Sciences Library, University of Manitoba Libraries, Winnipeg, MB, Canada.

(e-mail: me-linh.le@ umanitoba.ca) Dieter J. Schönwetter

University of Manitoba, Dr. Gerald Niznick College of Dentistry \& School of Dental Hygiene, Rady Faculty of Health Sciences, Winnipeg, MB, Canada.

(e-mail: dieter.schonwetter@umanitoba.ca)

*Corresponding Author

qAuthors have equal contribution College of Dentistry \& School of Dental

and restriction of social activities, were implemented to contain spreading of the disease. These changes, along with concerns of being infected, are likely to affect mental health and contribute to adverse psychological outcomes [4].

Several studies have assessed COVID-19 related experiences, behaviors, and attitudes among dental practitioners that varied among countries [5]-[7]. In the United Kingdom, a high level of anxiety was identified among hospital dental team members [8]. Their most prevalent fears were related to spreading the virus and its impact on family, friends, and personal health. German practitioners reported mild levels of stress, anxiety, and depression, with females and third gender respondents reporting higher levels than males [9]. Pre-existing medical 
conditions and a higher subjective overload contributed to increased psychological distress in Israeli dental practitioners and hygienists [10]. Although the majority of research focuses on anxiety, stress, depression and fear, studies examining other psychosocial aspects of COVID-19, especially after re-opening following the initial lockdown, are scarce.

The aim of the current study, which was conducted several months after the initial lockdown period of fear and uncertainty, was to assess the impact of COVID-19 outbreak on dental practitioners in the USA and Canada. It focused on a thorough understanding of human psychosocial reactions by evaluating the primary affects identified in Plutchik's wheel of emotions [11]. The dental practitioners were evaluated for their affective well-being, both during the periods of initial lockdown and after re-opening, behavioral impact, and cognitive responses. To the best of our knowledge, this is the first study to compare primary emotions on multiple levels during the COVID-19 pandemic. Through our findings, we emphasize on the need for standardized protocols and educational health sessions for healthcare professionals to enable positive functioning during periods of global crisis.

\section{Methodology}

\section{A. Study Design}

This cross-sectional study received ethical approval from the Southern Illinois University Edwardsville and the University of Manitoba Institutional Review Boards. Participation in the survey was an acknowledgement of consent to share information anonymously. The online survey questions defined the three theoretical constructions of affects, behaviors, and cognition. The questionnaires comprised of dichotomous, single choice, multiple choice, open ended and Likert response scale questions. The questions were branched into two broad categories of time, "during-" and "following-COVID-19 initial lockdown period". The initial lockdown is the period when elective dental care was officially suspended in the United States and Canada (March-April 2020). The survey was validated by a psychometrician and four dental practitioners. For ensuring construct validity, four dental practitioners were invited to complete the survey. Participants provided feedback as to the clarity of each survey item, the length of the survey and any issue that they had with the survey. The feedback provided by the participants was used to revise the survey. The psychometrician helped in refining the survey and developing the construct validity. Data for the study were collected between March and May 2021. Data were collected through the online survey platform Survey Monkey.

\section{B. Survey Distribution}

For distribution to dental academics, a letter of invitation, with the survey link, was sent to the Associate Deans of 67 US and 10 Canadian dental schools by the Associate Dean for Academic Affairs at Southern Illinois University School of Dental Medicine and the Associate Dean for Research at the University of Manitoba College of Dentistry respectively. They were requested to share the emails with their academician dentists. To be able to capture a better representation of all dental practitioners, invitation emails were sent to representatives of the state dental associations and local dental societies throughout the US and Canada. The survey was also distributed through professional forums.

\section{Statistical Analysis}

Demographic data along with several comparisons were used to explore the dental practitioners' psychosocial responses to COVID-19. First, descriptive statistics were generated to identify current practitioner trends, both during and following COVID-19 lockdown. Second, comparisons were made between cohort differences using gender, age cohort, country, and number of practice years as independent variables and measures of affects, behaviors, and cognitive responses as dependent variables using ANOVA test. Significant main effects were tested using Dunnett's t-tests. The COVID-19 lockdown and post lockdown measures were compared using Repeated General Linear Model. As an exploratory study, the alpha level was set at $p<0.05$.

\section{RESUlTS}

\section{A. Demographic Characteristics}

A total of 587 dental practitioners completed the online survey. As seen in Table I, responses reflect the current dental professional profiles reported in the USA and Canada [12], [13]. The representative participants were males $(57.4 \%)$, and from the USA (81.2\%, representing 34 states). The highest representations were from Illinois, followed by Nevada, Kentucky, Alaska, Missouri, and Michigan. Canadian participants represented eight provinces with the highest responses from British Columbia and Manitoba. Most practitioners were between the ages of 55-64 (29.5\%) and above $(21.6 \%)$. About $57.0 \%$ were general dentists, and $41.6 \%$ had been in practice for over 30 years. The specialists represented eleven American Dental Association recognized specialties. About $56.6 \%$ practitioners were primarily involved in private practice, and $22.8 \%$ in academia. The average setting for private practitioners was a small sized clinic with 1-4 chairs, dental assistants and associate partners respectively.

\section{B. Affective Impact}

Participants provided their affective responses to the COVID-19 pandemic on a 100-point sliding-scale anchored with Plutchik's primary bipolar emotions [11]. As seen in Table II, the strongest emotion experienced during the lockdown was sadness, followed by fear. Females exhibited higher fear than the males, whereas males experienced significant emotions of disgust on the situation. Participants aged 35-44 had higher fear scores than those in the $\geq 65$ age cohort $(p<0.05,65.26 \pm 4.77$ and 54.82 \pm 4.63$)$. Likewise, those with 11-20 years of dental experience were more fearful than those with over 30 years of experience $(p<0.05$; $65.46 \pm 4.34$ and 56.45 \pm 3.27 ). Following lockdown, anticipation ranked the highest among basic affects (Table II). Males displayed higher scores on anger and disgust during this phase. Canadians, in comparison to American participants, expressed more anger following the lockdown (Table II). At the same time, Canadians were trustful of the circumstances both during and following lockdown as compared to their US counterparts, who had higher scores on 
disgust. There were no significant differences in terms of fear, surprise, anticipation, sadness, and joy among the countries.

TABLE I: DEMOGRAPHIC CHARACTERISTICS OF PARTICIPATING DENTAL PRACTITIONERS $(\mathrm{N}=587)$

\begin{tabular}{|c|c|c|}
\hline Characteristics & Number & Percentage $(\%)$ \\
\hline \multicolumn{3}{|l|}{ Age (years) } \\
\hline $25-34$ & 59 & 10.1 \\
\hline $35-44$ & 110 & 18.7 \\
\hline $45-54$ & 110 & 18.7 \\
\hline $55-64$ & 173 & 29.5 \\
\hline$\geq 65$ & 127 & 21.6 \\
\hline Missing & 8 & 1.4 \\
\hline \multicolumn{3}{|l|}{ Gender } \\
\hline Male & 337 & 57.4 \\
\hline Female & 242 & 41.2 \\
\hline Other & 1 & 0.2 \\
\hline Do not wish to share & 2 & 0.3 \\
\hline Missing & 5 & 0.9 \\
\hline \multicolumn{3}{|l|}{ Country } \\
\hline USA & 483 & 82.3 \\
\hline Canada & 104 & 17.7 \\
\hline \multicolumn{3}{|l|}{ Discipline } \\
\hline General Dentist & 335 & 57.1 \\
\hline Specialist & 140 & 23.9 \\
\hline Did not specify & 112 & 19.1 \\
\hline \multicolumn{3}{|c|}{ Professional experience (years) } \\
\hline$<5$ & 42 & 7.2 \\
\hline $5-10$ & 68 & 11.6 \\
\hline $11-20$ & 113 & 19.3 \\
\hline $21-30$ & 112 & 19.1 \\
\hline$>30$ & 244 & 41.6 \\
\hline Missing & 8 & 1.4 \\
\hline \multicolumn{3}{|l|}{ Primary workplace } \\
\hline Academic & 134 & 22.8 \\
\hline Hospital-based & 15 & 2.6 \\
\hline Private practice & 332 & 56.6 \\
\hline Rural or remote & 79 & 13.5 \\
\hline Suburban & 170 & 29.0 \\
\hline Urban & 123 & 21.0 \\
\hline
\end{tabular}

A comparison between during and following lockdown phases yielded findings for each of Plutchik's emotional pairings (Table II). During lockdown, participants' scores were closer to the fear, low anticipation, sadness, and disgust ends of the scale. Following lockdown, their emotional scores reflected more anger, higher anticipation, lower joy, and lower levels of disgust.

The highest concerns of participants were over the risk of infecting family members, or not being able to take care of family and having to quarantine, if they contracted COVID19 infection. Many were worried about losing their staff and practice, not being able to provide care to patients, and feared that this could be the end of their career, whereas others expressed their anger and frustration over the government. Other reasons provided by respondents included mental stress, risk of developing long-term chronic effects of the infection, stress of obtaining medical care, and social stigma.

\section{Behavioral Impact}

During lockdown, $82.1 \%$ participants provided emergent dental care, whereas elective care was almost non-existent (9.4\%, Table III). Only about $54.2 \%$ dental practitioners had a sufficient supply of personal protective equipment (PPE) to take care of their patients' needs. With respect to country, American as compared to Canadian dental practitioners had a sufficient supply of PPE $\left[\chi^{2}(1, \mathrm{n}=525)=101.02, p<\right.$ $0.00001]$ and were thus better equipped for emergent care $\left[\chi^{2}\right.$ $(1, \mathrm{n}=530)=15.72, p<0.0001]$. Those in medium-sized private practice clinics showed a stronger correlation with the ability to provide emergent care $\left[\chi^{2}(2, \mathrm{n}=418)=11.37, p<\right.$ 0.01].

About $56.7 \%$ participants provided remote patient consultations or teledentistry. The most common form of patient communication was video calling (54.5\%) on Zoom, FaceTime, Skype, or WhatsApp (Table III). This was followed by text $(22.9 \%$, in the form of email or text messaging) and voice formats $(6.6 \%$, as phone conversation, Table III). Private practitioners mainly used voice $(p<$ $0.0001)$ and text formats $(p<0.05)$ for teledentistry during the lockdown. Small office providers $(p<0.01)$ and dental academics $(p<0.05)$, however, preferred contacting the patients through video calls. Canadian, compared to American dental practitioners, were significantly involved in performing remote consultations $\left[\chi^{2}(1,529)=21.73, p<\right.$ $0.0001]$, primarily through video calling.

\section{Cognitive Impact}

Practitioners were asked about their experiences during the lockdown period to assess the cognitive impact of the pandemic. Among these, lack of social interaction scored the highest on a 5-point Likert scale $(\mathrm{M}=3.67)$, followed by concern for contracting COVID-19 infection and stress from frequent exposure to distressing media coverage (Table IV, $M=3.42$ ). Next, the respondents agreed that they were able to spend quality time with family $(\mathrm{M}=2.95)$; experienced financial constraint ( $M=2.87)$; and lastly, got some time to rest, were able to engage in hobbies and could focus more on health (Table IV, $\mathrm{M}=2.78$ ).

If participants contracted COVID-19 infection, their highest concern would be for health-related stress and fear of spreading the infection (Table IV, M = 3.45 each). The youngest participants expressed less concern for healthrelated stress. Next were concerns for financial stress $(\mathrm{M}=$ $2.98)$ and social stigma $(\mathrm{M}=2.21)$. Furthermore, majority of participants $(79.4 \%)$ were aware of which authority to contact if their patient was suspected of having COVID-19 infection (Table IV). In general, this awareness was higher in Canadians than their American counterparts $(p<0.05,4.07 \pm$ 0.23 and $3.69 \pm 0.13)$. For the most part, participants as a group $(91.0 \%)$ were very receptive in terms of receiving the COVID-19 vaccine (Table IV).

\section{DISCUSSION}

Every pandemic has psychological implications especially when there is a sharp rise in the number of cases and mortality rates. COVID-19 has significantly affected the healthcare workers because of its contagious nature and their direct close contact with patients. Most studies that assessed the psychological impact of COVID-19 on dental practitioners during the lockdown period focused on major parameters including stress, fear, anxiety, and depression. The current study uniquely compares several primary emotions identified in the classic research of Plutchik [11] in two prominent phases of this pandemic: during and after the initial lockdown. It is important to interpret these findings in the context of COVID-19 outbreak since a subgroup of dental practitioners could have been experiencing psychological issues even prior to the pandemic. 
TABLE II. EMOTIONAL RESPONSES OF DENTAL PRACTITIONERS ON A 100-POINT SCALE DURING AND FOLLOWING COVID-19 LOCKDOWN PERIOD

\begin{tabular}{|c|c|c|c|c|c|c|}
\hline \multirow{2}{*}{$\begin{array}{l}\text { Emotional } \\
\text { variable }\end{array}$} & \multirow{2}{*}{ Time } & \multirow{2}{*}{$\begin{array}{l}\text { General Responses, } \\
\text { Mean } \pm \text { SEM }(\mathrm{N})\end{array}$} & \multicolumn{2}{|c|}{ Responses per Gender, Mean \pm SEM $(\mathrm{N})$} & \multicolumn{2}{|c|}{ Responses per Country, Mean \pm SEM $(\mathrm{N})$} \\
\hline & & & Female & Male & USA & Canada \\
\hline \multirow{4}{*}{ Anger-Fear } & During LD & $60.54 \pm 1.04(510)$ & $65.44 \pm 1.48(220)$ & $56.82 \pm 1.41(290)$ & $60.17 \pm 1.12(420)$ & $62.33 \pm 2.69(93)$ \\
\hline & & & \multicolumn{2}{|c|}{$\begin{array}{c}{ }^{\ddagger} \mathrm{F}(1,508)=17.29, \mathrm{MSE}=9286.01, \\
p<0.001\end{array}$} & \multicolumn{2}{|c|}{ NS } \\
\hline & After LD & $44.22 \pm 1.02(484)$ & $48.60 \pm 1.42(206)$ & $40.98 \pm 1.40(278)$ & $43.24 \pm 1.10(399)$ & $49.10 \pm 2.58(86)$ \\
\hline & \multicolumn{2}{|c|}{$\begin{array}{c}{ }^{£} \mathrm{~F}(1,470)=246.23, \mathrm{MSE}= \\
56463.33, p<0.0001\end{array}$} & \multicolumn{2}{|c|}{$\begin{array}{c}{ }^{¥} \mathrm{~F}(1,482)=14.03, \mathrm{MSE}=6867.92, \\
p<0.0001\end{array}$} & \multicolumn{2}{|c|}{$\begin{array}{c}{ }^{\sharp} \mathrm{F}(1,483)=4.87 ; \mathrm{MSE}=499.53 ; \\
p=0.030\end{array}$} \\
\hline \multirow{4}{*}{$\begin{array}{l}\text { Surprise- } \\
\text { Anticipation }\end{array}$} & During LD & $51.88 \pm 1.02(516)$ & $53.14 \pm 1.60(217)$ & $50.96 \pm 1.33(299)$ & $52.55 \pm 1.11(425)$ & $48.41 \pm 2.58(94)$ \\
\hline & & & \multicolumn{2}{|c|}{ NS } & \multicolumn{2}{|c|}{ NS } \\
\hline & After LD & $60.30 \pm 1.04(505)$ & $60.76 \pm 1.60(217)$ & $59.96 \pm 1.37(288)$ & $60.80 \pm 1.12(419)$ & $57.93 \pm 2.76(87)$ \\
\hline & ${ }^{f} \mathrm{~F}(1,394)$ & $\begin{array}{l}23, \mathrm{MSE}=3890.86 \\
<0.01\end{array}$ & \multicolumn{2}{|c|}{ NS } & \multicolumn{2}{|c|}{ NS } \\
\hline \multirow{4}{*}{ Sadness-Joy } & During LD & $33.27 \pm 1.07(482)$ & $34.55 \pm 1.51(200)$ & $32.36 \pm 1.47(282)$ & $33.57 \pm 1.15(396)$ & $31.89 \pm 2.64(89)$ \\
\hline & & & \multicolumn{2}{|c|}{ NS } & \multicolumn{2}{|c|}{ NS } \\
\hline & After LD & $53.44 \pm 1.20(494)$ & $53.12 \pm 1.74(211)$ & $53.67 \pm 1.65(283)$ & $53.94 \pm 1.31(406)$ & $50.74 \pm 3.00(89)$ \\
\hline & $\begin{array}{r}{ }^{£} \mathrm{~F}(1,4 \\
96 \\
\end{array}$ & $\begin{array}{l}=248.57, \mathrm{MSE}= \\
30 ; p<0.0001\end{array}$ & \multicolumn{2}{|c|}{ NS } & \multicolumn{2}{|c|}{ NS } \\
\hline \multirow{3}{*}{ Disgust-Trust } & & & \multicolumn{2}{|c|}{$\begin{array}{c}{ }^{{ }^{7}} \mathrm{~F}(1,499)=8.50 ; \mathrm{MSE}=748.36 ; p= \\
0.004\end{array}$} & \multicolumn{2}{|c|}{$\begin{array}{c}{ }^{{ }^{q}} \mathrm{~F}(1,502)=9.13 ; \mathrm{MSE}=744.47 ; p= \\
0.001\end{array}$} \\
\hline & After LD & $47.22 \pm 1.34(486)$ & $52.39 \pm 1.88(207)$ & $43.39 \pm 1.84(279)$ & $46.00 \pm 1.45(401)$ & $52.83 \pm 3.36(86)$ \\
\hline & ${ }^{£} \mathrm{~F}(1,474)$ & $\begin{array}{l}13, \mathrm{MSE}=1475.77 \\
<0.05\end{array}$ & \multicolumn{2}{|c|}{$\begin{array}{c}{ }^{\sharp} \mathrm{F}(1,484)=11.29, \mathrm{MSE}=9616.5, \\
p<0.001\end{array}$} & \multicolumn{2}{|c|}{$\begin{array}{c}{ }^{{ }^{\ddagger}} \mathrm{F}(1,485)= \\
p=0.82 ; \mathrm{MSE}=863.22,\end{array}$} \\
\hline
\end{tabular}

F, degrees of freedom; LD, lockdown; MSE, mean squared error; NS, not significant; n, number; SEM, standard error mean; ¥ ANOVA; £ Repeated Measures ANOVA.

\begin{tabular}{|c|c|c|c|c|}
\hline Variable & No & Yes & Total & Missing \\
\hline \multicolumn{5}{|c|}{ During COVID-19 lockdown period, was your workplace able to provide... } \\
\hline Elective dental care & $475(90.6 \%)$ & $49(9.4 \%)$ & 524 & 63 \\
\hline Emergent dental care & $94(17.9 \%)$ & $431(82.1 \%)$ & 525 & 62 \\
\hline Sufficient supply of PPE & $243(45.8 \%)$ & $287(54.2 \%)$ & 530 & 57 \\
\hline \multicolumn{5}{|c|}{ Did you conduct any form of remote consultations (teledentistry) during the COVID-19 lockdown period? } \\
\hline & $229(43.3 \%)$ & $300(56.7 \%)$ & 529 & 58 \\
\hline \multicolumn{5}{|c|}{ Which of the following did you use for teledentistry during COVID-19 lockdown period? } \\
\hline $\begin{array}{l}\text { Voice format: telephone } \\
\text { Text format: email, text }\end{array}$ & $213(93.4 \%)$ & $15(6.6 \%)$ & 228 & 359 \\
\hline $\begin{array}{l}\text { messaging, postal/courier } \\
\text { service, etc. }\end{array}$ & $172(77.1 \%)$ & $51(22.9 \%)$ & 223 & 364 \\
\hline $\begin{array}{l}\text { Video format: Zoom, } \\
\text { FaceTime, Skype, } \\
\text { WhatsApp, etc. }\end{array}$ & $100(45.5 \%)$ & $120(54.5 \%)$ & 220 & 367 \\
\hline
\end{tabular}

TABLE IV: RESPONSES OF DENTAL PRACTITIONERS TO ASSESS THE COGNITIVE IMPACT OF COVID-19 PANDEMIC (N=587)

\begin{tabular}{|c|c|c|c|c|c|c|c|c|c|}
\hline & $\begin{array}{l}\text { Not at all } \\
\mathrm{N}(\%)\end{array}$ & $\begin{array}{l}\text { A little } \\
\mathrm{N}(\%)\end{array}$ & $\begin{array}{l}\text { A moderate } \\
\text { amount }\end{array}$ & $\begin{array}{c}\text { A lot } \\
\mathrm{N}(\%)\end{array}$ & A great deal & Total & Missing & Mean & $\begin{array}{l}\text { Std } \\
\text { Dev }\end{array}$ \\
\hline \multicolumn{10}{|c|}{ To what extent did you experience each of the following during COVID-19 lockdown... } \\
\hline Lack of social interaction & $39(6.6)$ & $82(14.0)$ & $85(14.5)$ & $142(24.2)$ & $187(31.9)$ & $535(91.3)$ & $52(8.8)$ & 3.67 & 1.29 \\
\hline $\begin{array}{l}\text { Media-induced stress, concerned } \\
\text { about contracting COVID-19 }\end{array}$ & $42(7.2)$ & $100(17.1)$ & $129(22.0)$ & $125(21.3)$ & $141(24.1)$ & $537(91.6)$ & $50(8.5)$ & 3.42 & 1.27 \\
\hline $\begin{array}{l}\text { Was able to spend quality time } \\
\text { with family }\end{array}$ & $80(13.7)$ & $156(26.6)$ & $98(16.7)$ & $117(20.0)$ & $86(14.7)$ & 537 (91.6) & $50(8.5)$ & 2.95 & 1.32 \\
\hline Financial constraint & $118(20.1)$ & $116(19.8)$ & $117(20.0)$ & $85(14.5)$ & $98(16.7)$ & $534(91.1)$ & $53(9.0)$ & 2.87 & 1.41 \\
\hline $\begin{array}{l}\text { Got time to rest, able to engage in } \\
\text { my hobbies, could focus on my } \\
\text { health }\end{array}$ & $100(17.1)$ & $154(26.3)$ & $116(19.8)$ & $99(16.9)$ & $68(11.6)$ & 537 (91.6) & $50(8.5)$ & 2.78 & 1.29 \\
\hline \multicolumn{10}{|c|}{ If you were to contract COVID-19 infection, to what extent would each of the following concern you? } \\
\hline Health related stress & $38(7.4)$ & $110(21.3)$ & $110(21.3)$ & $100(19.3)$ & $159(30.8)$ & $517(88.2)$ & $70(11.9)$ & 3.45 & 1.32 \\
\hline Social stigma & $201(39.0)$ & $142(27.5)$ & $81(15.7)$ & $47(9.1)$ & $45(8.7)$ & $516(88.1)$ & $71(12.1)$ & 2.21 & 1.29 \\
\hline Financial stress & $88(17.3)$ & $136(26.7)$ & $93(18.2)$ & $84(16.5)$ & $109(21.4)$ & $510(87.0)$ & $77(13.1)$ & 2.98 & 1.41 \\
\hline $\begin{array}{l}\text { External Factors: getting infected } \\
\text { at your workplace, spreading } \\
\text { COVID-19 }\end{array}$ & $63(12.3)$ & $82(16.0)$ & $92(17.9)$ & $113(22.0)$ & $164(31.9)$ & $514(87.7)$ & $73(12.4)$ & 3.45 & 1.39 \\
\hline $\begin{array}{l}\text { If your patient is suspected of } \\
\text { COVID-19 infection, are you } \\
\text { aware of which authority to } \\
\text { contact? }\end{array}$ & $46(8.9)$ & $61(11.8)$ & $74(14.3)$ & $131(25.3)$ & $206(39.8)$ & $518(88.4)$ & $69(11.8)$ & 3.75 & 1.32 \\
\hline $\begin{array}{l}\text { To what extent are you receptive } \\
\text { to receiving the COVID-19 } \\
\text { vaccine? }\end{array}$ & $29(5.7)$ & $17(3.3)$ & $17(3.3)$ & $23(4.5)$ & $427(83.2)$ & $513(87.5)$ & $74(12.6)$ & 4.56 & 1.09 \\
\hline
\end{tabular}

This study highlights interesting trends of the primary emotions that differed between genders, age groups, number of practice years, and countries. During COVID-19 lockdown, females demonstrated significantly higher scores of fear. Whereas following lockdown, males were more fearful and angrier. Interestingly, higher scores on trust and anger were respectively reported during and following COVID-19 lockdown by the Canadians. Dental practitioners 
primarily involved in academia, the specialists, and those with small-sized private practices showed similar trends. Studies that documented the psychological impact of COVID-19 pandemic report that dental practitioners were most fearful of infecting family members or being infected by the patient or co-workers [14]. Apprehension for hospitalization and social isolation, possibility of infection and increase in mortality rates are other reported causes of fear [15]. Some authors hypothesized that lack of knowledge about the biology and transmission of the virus could have resulted in an aggravated fear among these participants [15], [16]. Dental practitioners with elderly and immunocompromised family members or those who commonly performed aerosol generating procedures were more likely to be intensely fearful [17], [18]. It is interesting to note that Italian practitioners who experienced low levels of fear had fewer symptoms of depression and perceived job insecurity [18]. On the contrary, females, younger individuals, and those with less work experience were better at overcoming their fears [19]. People with longer work experience were more efficient. This coincides with the findings of our study in which practitioners with more work experience were less fearful of the situation, which partly may have been because of their previous experience with pandemics. In another study feelings of intense anger were reported by only $9.3 \%$ of Italian respondents [14]. A study that compared psychological outcomes during quarantine because of the Middle East Respiratory Syndrome (MERS) with later outcomes observed that during quarantine, $17 \%$ respondents showed feelings of anger, whereas this was reduced to $6 \%$ four-to-six months after quarantine [20]. Similar emotions were recorded at the time of HIV outbreak when dental practitioners refused to treat patients due to unreasonable fear, homophobia, and the fear of financial loss [21].

In the present study, male practitioners, during and following COVID-19 lockdown, demonstrated significantly higher scores on disgust. Canadians and academics showed higher trust throughout the pandemic. To the best of our knowledge, the psychological impact of any pandemic on primary emotions of disgust and trust has not been assessed. It is important to mention that of the 587 participants in this study, the highest response rates during the lockdown were for surprise-anticipation (88.57\%) and anger-fear (87.54\%). The lowest number of responses were for sadness-joy and anger-fear during and following the lockdown phases respectively. Of the very few studies that assessed sadness, one reported that only $12.6 \%$ dentists felt intensely sad during the COVID-19 lockdown [14]. A recent review on the effects of quarantine in previous outbreaks reported sadness in $18 \%$ respondents [22].

It is noteworthy to mention that practicing during the pandemic has been a first-time experience for many young dental practitioners, and about $50 \%$ of them perceived this as the most dangerous experience [23]. This in turn has led to several behavioral modifications. Tysiac-Mista and Dziedzic [24] documented that male practitioners in Poland, in comparison to female participants, preferred to continue their clinical work during the lockdown. This was partly due to having young children at home, home schooling, pregnancy, etc. Since the government measures permitted only emergency procedures, a high number of dental practitioners limited their practice to emergency care [14]. In our study, $82.1 \%$ participants provided only emergent dental care during the lockdown period, and the American practitioners were better equipped for this service. More recently, dental practitioners have started performing elective procedures which were postponed for a long time due to the impact of COVID-19 [14].

During the lockdown, teledentistry and e-prescriptions were encouraged to minimize the number of patient visits to dental offices [24]. In a survey study from India, about $46.3 \%$ of respondents agreed to teleconferencing and delaying any non-emergent procedures [23]. Our study showed just over half of the participating dental practitioners $(56.7 \%)$ provided teledentistry, with Canadians being more involved than their American colleagues. About $66.0 \%$ of dentists in Poland suspended their clinical activities due to the rise in number of COVID-19 cases and their dental offices not being equipped with support to cater to patient care [24]. In our study, only about $54.2 \%$ dental practitioners had a sufficient supply of PPE to take care of their patients' needs.

COVID-19 on the whole has resulted in many stressful events including loss of freedom, separation from family, and inability to work [25], [26]. Among other factors, the sudden suspension of research activities and job insecurity associated with the pandemic have added to increased stress levels in academics [27]. Long working hours, untimely emergency calls, state of quarantine, and separation from family has put healthcare workers under extreme stress, anxiety and frustration [28]. In addition, misinformation by media, and uncertainty of returning to normality also increased the anxiety level [8]. A global study that assessed anxiety levels from 30 countries reported that $90 \%$ of the respondents reported fear of getting infected from patients or coworkers [15]. Some dentists even discontinued their practices temporarily due to the fear of infecting family and colleagues at work [24]. In our study, 63.0\% dental practitioners reported to have a moderate to a great deal of concern for being infected. A similar extent of concern was expressed for spreading the infection to friends and family. These were followed by concerns for financial stress, with higher concern identified among private practitioners, and social stigma.

One of the limitations of this study was that due to the cross-sectional nature of the study, a causal relationship could not be proved. Secondly, the timing of release of the questionnaire could have caused digital fatigue among practitioners resulting in a reduced participation. The results of this study serve as a guide for practice modifications that better prepare the dental practitioners for the pandemic crisis. The findings provide insights to various significant mental health states that have not been reported so far. This definitely demands additional studies that explore the broader scope of psychological impact on the profession. It is hoped that this will help in further developing research in less explored areas, guide policy changes or modifications and enhance education/health care planning.

\section{CONClusion}

Based on the limitations of the current study, the following conclusions were derived: 
- The psychological consequences of COVID-19, in terms of primary emotions, behaviors, and cognition, exist and vary in dental practitioners both during and after the initial lockdown.

- The scarcity of literature focusing on these basic emotions during similar outbreaks, definitely calls attention for pursuing more research in these areas as they significantly contribute to the overall psychological health of professionals especially in times of crises.

- Given the emotions reported by dental practitioners, it would be of value to provide remote psychological support such as free texts, phone, and video calls to support mental health.

- Monitoring of potential emerging mental disorders associated with COVID-19 is extremely important and should be considered a central element in the pandemic managing taskforce.

- This study emphasizes on the need for development of standardized protocols and pandemic-related educational seminars to better prepare healthcare professionals during times of global crisis.

\section{ACKNOWLEDGMENT}

The authors are thankful to Drs. William Goebel, Southern Illinois University School of Dental Medicine, Alton, Indraneel Bhattacharyya, University of Florida College of Dentistry, Gainesville, Sylvia Todescan and Reda Elgazzar from the University of Manitoba, Dr. Gerald Niznick College of Dentistry and School of Dental Hygiene, Rady Faculty of Health Sciences, University of Manitoba, Winnipeg, Manitoba, Canada, for providing feedback and validating the initial questionnaire. We would also like to thank Dr. Saulius Drukteinis, Associate Dean for Academic Affairs, Southern Illinois University, and Dr. Rajinder Bhullar, Associate Dean (Research), Dr. Gerald Niznick College of Dentistry and School of Dental Hygiene, University of Manitoba, for distributing the survey to the American and Canadian dental schools respectively. The authors would like to acknowledge the dental associations and dental societies for distributing the survey among their members, and all participants for their contribution.

\section{FUNDING}

No funding was obtained for this study.

\section{CONFLICT OF INTEREST}

Authors declare that they do not have any conflict of interest.

\section{REFERENCES}

[1] Sohrabi C, Alsafi Z, O'Neill N, Khan M, Kerwan A, Al-Jabir A, et al. World Health Organization declares global emergency: A review of the 2019 novel coronavirus (COVID-19). Int J Surg. 2020 Apr;76:71-6.

[2] Meng L, Hua F, Bian Z. Coronavirus Disease 2019 (COVID-19): Emerging and Future Challenges for Dental and Oral Medicine. J Dent Res. 2020 May;99(5):481-7.
[3] Spagnuolo G, De Vito D, Rengo S, Tatullo M. COVID-19 Outbreak: An Overview on Dentistry. Int J Environ Res Public Health. 2020 Mar $22 ; 17(6)$.

[4] Asmundson GJG, Taylor S. How health anxiety influences responses to viral outbreaks like COVID-19: What all decision-makers, health authorities, and health care professionals need to know. J Anxiety Disord. 2020 Apr;71:102211.

[5] Suryakumari VBP, Pallavi Reddy Y, Yadav SS, Doshi D, Surekha Reddy V. Assessing Fear and Anxiety of Corona Virus Among Dental Practitioners. Disaster Med Public Health Prep. 2020 Sep 11:1-6.

[6] Wang C, Pan R, Wan X, Tan Y, Xu L, Ho CS, et al. Immediate Psychological Responses and Associated Factors during the Initial Stage of the 2019 Coronavirus Disease (COVID-19) Epidemic among the General Population in China. Int J Environ Res Public Health. 2020 Mar 6;17(5).

[7] Uziel N, Gilon E, Meyerson J, Levin L, Khehra A, Emodi-Perlman A, et al. Dental personnel in Israel, Canada, and France during the COVID-19 pandemic: attitudes, worries, emotional responses, and posttraumatic growth. Quintessence Int. 2021;0(0):444-53.

[8] Mahendran K, Patel S, Sproat C. Psychosocial effects of the COVID19 pandemic on staff in a dental teaching hospital. Br Dent J. 2020 Jul;229(2):127-32.

[9] Mekhemar M, Attia S, Dorfer C, Conrad J. The Psychological Impact of the COVID-19 Pandemic on Dentists in Germany. J Clin Med. 2021 Mar 2;10(5).

[10] Shacham M, Hamama-Raz Y, Kolerman R, Mijiritsky O, Ben-Ezra M, Mijiritsky E. COVID-19 Factors and Psychological Factors Associated with Elevated Psychological Distress among Dentists and Dental Hygienists in Israel. Int J Environ Res Public Health. 2020 Apr $22 ; 17(8)$.

[11] Plutchik R. Emotion, a psychoevolutionary synthesis. New York: Harper \& Row; 1980.

[12] American Dental Association. ADA Health policy institute - Dental workforce in the U.S.; 2021. https://www.ada.org/en/scienceresearch/health-policy-institute/dental-statistics/workforce. Accessed September 29, 2021.

[13] American Dental Education Association. ADEA Snapshot of dental education 2019-20. 2019. https://www.adea.org/uploadedFiles/ADEA/Content_Conversion_Fin al/deansbriefing/2019-20_ADEA_Snapshot_of_Dental_Education. Accessed September 27, 2021.

[14] Consolo U, Bellini P, Bencivenni D, Iani C, Checchi V. Epidemiological Aspects and Psychological Reactions to COVID-19 of Dental Practitioners in the Northern Italy Districts of Modena and Reggio Emilia. Int J Environ Res Public Health. 2020 May 15;17(10).

[15] Ahmed MA, Jouhar R, Ahmed N, Adnan S, Aftab M, Zafar MS, et al Fear and Practice Modifications among Dentists to Combat Novel Coronavirus Disease (COVID-19) Outbreak. Int J Environ Res Public Health. 2020 Apr 19;17(8).

[16] Laureano C, Camilla I, Lunna F, Myroslav G-K, Leite CA, Yasemin Y. Mental Health of Dentists during the COVID-19 Pandemic: A critical literature review. Journal of International Dental \& Medical Research. 2021;14(1):192-202.

[17] Aly MM, Elchaghaby MA. Impact of novel coronavirus disease (COVID-19) on Egyptian dentists' fear and dental practice (a crosssectional survey). BDJ Open. 2020;6:19.

[18] Gasparro R, Scandurra C, Maldonato NM, Dolce P, Bochicchio V, Valletta A, et al. Perceived Job Insecurity and Depressive Symptoms among Italian Dentists: The Moderating Role of Fear of COVID-19. Int J Environ Res Public Health. 2020 Jul 24;17(15).

[19] Shirahmadi S, Seyedzadeh-Sabounchi S, Khazaei S, Bashirian S, Miresmaeili AF, Bayat Z, et al. Fear control and danger control amid COVID-19 dental crisis: Application of the Extended Parallel Process Model. PLoS One. 2020;15(8):e0237490.

[20] Jeong H, Yim HW, Song YJ, Ki M, Min JA, Cho J, et al. Mental health status of people isolated due to Middle East Respiratory Syndrome. Epidemiol Health. 2016;38:e2016048.

[21] Giambalvo AM. Treatment of the HIV-infected patient. J Am Dent Assoc. 1997 Oct;128(10):1350, 2.

[22] Brooks SK, Webster RK, Smith LE, Woodland L, Wessely S, Greenberg N, et al. The psychological impact of quarantine and how to reduce it: rapid review of the evidence. Lancet. 2020 Mar 14;395(10227):912-20.

[23] Arora S, Abullais Saquib S, Attar N, Pimpale S, Saifullah Zafar K, Saluja P, et al. Evaluation of Knowledge and Preparedness Among Indian Dentists During the Current COVID-19 Pandemic: A CrossSectional Study. J Multidiscip Healthc. 2020;13:841-54.

[24] Tysiac-Mista M, Dziedzic A. The Attitudes and Professional Approaches of Dental Practitioners during the COVID-19 Outbreak in 
Poland: A Cross-Sectional Survey. Int J Environ Res Public Health. 2020 Jun 30;17(13).

[25] Mijiritsky E, Hamama-Raz Y, Liu F, Datarkar AN, Mangani L, Caplan $\mathrm{J}$, et al. Subjective Overload and Psychological Distress among Dentists during COVID-19. Int J Environ Res Public Health. $2020 \mathrm{Jul}$ $14 ; 17(14)$.

[26] Vergara-Buenaventura A, Chavez-Tunon M, Castro-Ruiz C. The Mental Health Consequences of Coronavirus Disease 2019 Pandemic in Dentistry. Disaster Med Public Health Prep. 2020 Dec;14(6):e31e4.

[27] Ammar N, Aly NM, Folayan MO, Khader Y, Virtanen JI, Al-Batayneh $\mathrm{OB}$, et al. Behavior change due to COVID-19 among dental academicsThe theory of planned behavior: Stresses, worries, training, and pandemic severity. PLoS One. 2020;15(9):e0239961.

[28] Khanagar SB, Al-Ehaideb A, Vishwanathaiah S, Maganur PC, Varadarajan S, Patil S. Depression, Anxiety, and Psychological Distress among Healthcare Providers during the Outbreak of the Lifethreatening Coronavirus Disease (COVID-19). J Contemp Dent Pract. 2020 May 1;21(5):471-2.

[29] Johnston KJ, Hammond G, Meyers DJ, Joynt Maddox KE. Association of race and ethnicity and medicare program type with ambulatory care access and quality measures. JAMA. 2021 Aug 17;326(7):628-636. doi: 10.1001/jama.2021.10413. 